Original article

\title{
Correlates of current rapid-cycling bipolar disorder: Results from the Italian multicentric RENDiBi study
}

\author{
Massimiliano Buoli,**, Bruno Mario Cesana ${ }^{\mathrm{b}}$, Giuseppe Maina $^{\mathrm{c}}$, Andreas Conca $^{\mathrm{d}}$, \\ Andrea Fagiolini ${ }^{\mathrm{e}}$, Luca Steardo Jr. ${ }^{\mathrm{f}}$, A. Carlo Altamura ${ }^{\mathrm{a}}$, Bernardo Dell'Osso ${ }^{\mathrm{g}, \mathrm{h}, \mathrm{i}}$, \\ on behalf of the ISBD Italian Chapter Epidemiologic Group \\ a Department of Psychiatry, University of Milan, Fondazione IRCCS Ca'Granda Ospedale Maggiore Policlinico, Via F. Sforza 35, 20122, Milan, Italy \\ ${ }^{\mathrm{b}}$ Department of Clinical Sciences and Community Health, Unit of Medical Statistics, Biometry and Bioinformatics "Giulio A. Maccacaro", Faculty of Medicine \\ and Surgery, University of Milan, Milan, Italy \\ ${ }^{\mathrm{c}}$ Department of Mental Health, "San Luigi-Gonzaga" Hospital, University of Turin, Orbassano, Turin, Italy \\ d Department of Psychiatry, Bolzano, Italy \\ e Department of Mental Health and Department of Molecular Medicine, University of Siena Medical Center, Siena, Italy \\ ${ }^{\mathrm{f}}$ Psychiatric Unit, Department of Health Sciences, University Magna Graecia, Catanzaro, Italy \\ g Department of Biomedical and Clinical Sciences "Luigi Sacco", Psychiatry Unit 2, ASST-Fatebenefratelli-Sacco, via G.B.Grassi 74, 20157 Milan, Italy \\ ${ }^{\mathrm{h}}$ Department of Psychiatry and Behavioral Sciences, Stanford University, CA, USA \\ i CRC "Aldo Ravelli" for Neurotechnology and Experimental Brain Therapeutics, University of Milan, Italy
}

\section{A R T I C L E I N F O}

\section{Article history:}

Received 12 February 2019

Received in revised form 23 July 2019

Accepted 5 September 2019

Available online 21 September 2019

\section{Keywords:}

Bipolar disorder (BD)

Rapid-cycling (RC)

Socio-demographic features

Clinical variables

\begin{abstract}
A B S T R A C T
Background: we aimed to compare socio-demographic and clinical differences between patients with versus without current $\mathrm{RC}$ in order to detect clinical factors that may favor early diagnosis and personalized treatment.

Methods: A total of 1675 patients (males: $\mathrm{n}=714$ and females: $\mathrm{n}=961$; bipolar $1: \mathrm{n}=1042$ and bipolar 2: $\mathrm{n}=633$ ) from different psychiatric clinics were grouped and compared according to the current presence of RC in terms of socio-demographic and clinical variables. Chi-squared tests for qualitative variables and Student's $t$ tests for quantitative variables were executed for group comparison, and multivariable logistic regressions were performed, considering the current presence of RC as dependent variable, and sociodemographic/clinical factors as independent variables.

Results: Female gender (male versus female: $\mathrm{OR}=0.64, \mathrm{p}=0.04$ ), unidentifiable prevalent polarity (versus depressive polarity: $\mathrm{OR}=1.76, \mathrm{p}=0.02$; versus manic polarity: $\mathrm{OR}$ : $2.86, \mathrm{p}<0.01$ ) and hospitalization in the last year (no versus yes: $O R=0.63, p=0.02$ ) were found to be associated with $R C$ in the final multivariable regression analysis.

Conclusions: RC in BD seems to be more prevalent in female gender and associated with some unfavorable clinical features, such as an increased risk of hospitalization. These aspects should be taken into account in the management and monitoring of RC versus non-RC patients.
\end{abstract}

(C) 2019 Elsevier Masson SAS. All rights reserved.

\section{Introduction}

Bipolar Disorder (BD) is a prevalent psychiatric condition, associated with high disability and poor social functioning [1]. This condition affects about $2.4 \%$ of the adult population lifetime if the broader definition of bipolar spectrum disorders is considered [2], and, although prevalence rates may be different between countries for methodological issues [3], severity and impact of BD are similar internationally [2]. In Italy about $3 \%$ of the general population

\footnotetext{
* Corresponding author.

E-mail address: massimiliano.buoli@unimi.it (M. Buoli).
}

seems to suffer of a bipolar spectrum disorder [4]. BD has a tremendous impact on patients' and caregivers' lives and it has been associated with high rates of divorces and volatility of social relationships [5]. Clinical management of patients with BD can be challenging in light of frequent juvenile onset [6], misdiagnosis with other psychiatric diagnoses (especially major depression and psychotic disorders) [7] and high suicidal risk [8].

Several clinical factors have been associated with poor outcome of patients with BD including early onset [9], elderly status [10], long duration of illness [11], long duration of untreated illness [12], lifetime presence of psychotic symptoms [13-15] or rapid-cycling (RC) [16], while the role of other variables, such as gender, on BD outcome is still controversial [17]. Of note, RC, defined by at least 
4 mood episodes over a 12 -month period, is reported by a significant part of patients with BD [18] and different factors have been reported to increase the risk of RC in $\mathrm{BD}$, including early age at onset [19] and tricyclic antidepressant treatment [18]. Some authors argue that RC can be a transient phenomenon of patients with BD [20] and that treatment with antidepressants may worsen its outcome over the course of BD [21]. Of note, RC patients with BD (RCBD) were found to have more mood episodes, suicide attempts [22], and more frequent comorbidity with obesity [23] and diabetes [24] than subjects affected by non-rapid cycling BD (NRCBD). Associated unfavourable clinical features and frequent medical comorbidity both contribute to the poor psychosocial functioning of RC patients, especially in terms of work impairment [25].

Pharmacotherapy may be less effective in RC than in NRC patients with $\mathrm{BD}$, making long-term stabilization of these subjects particularly difficult [26]. Patients with RCBD may benefit of combined pharmacotherapy [27], or of augmentative psychological or biological approaches to pharmacological treatment [28], but available data are far to be conclusive about this topic [16]. Overall, RCBD appears to be a subtype of illness associated with worse outcome, potentially characterized by more severe biological abnormalities. More specifically, patients with RCBD (compared to NRCBD) seem to present more oxidative stress and a higher susceptibility to hypothyroidism and insulin resistance [29].

Taken as a whole, different clinical factors may contribute to the overall severity of RCBD compared to NRCBD, some of which are still controversial, such as early age at onset [30]. The search or the confirmation of clinical predictors of $\mathrm{RC}$ is motivated by the possibility of implementing specific prevention strategies that avoid the onset of this more severe form of illness, and by the elaboration of personalized treatments for these patients. In this framework, the purpose of the present study was to investigate, in a large representative sample of Italian patients with $\mathrm{BD}$, a wide series of socio-demographic and clinical features common to and differentiating RCBD and NRCBD patients, with the aim to identify factors that may favor an early diagnosis and a personalized treatment for patients with RCBD.

\section{Methods}

A total sample of 1675 patients with $\mathrm{BD}$, corresponding to $83.8 \%$ of a target considered as optimal in the planning phase of the exploratory survey, was enrolled from different Italian psychiatric clinics in the context of RENDiBi project (National Epidemiological Research on Bipolar Disorder). The data have been collected for patients consecutively afferent to the different clinics between $1^{\text {st }}$ April 2014 and $31^{\text {st }}$ March 2015. The included Italian centres were the following: Milan-Fondazione IRCCS Policlinico; GenoaInpatient and Outpatient Clinics; Turin-S. Luigi Gonzaga; BozenInpatient and Outpatients Clinics; Naples-Second University (SUN); Siena-Inpatient Clinic; Pisa-Inpatient Clinic; Rome-Tor Vergata; Bari-Inpatient and Outpatient Clinics; Naples- Federico II; Foggia-Inpatient and Outpatient Clinics; Turin-Molinette; Rome-Sant'Andrea Hospital; Rome-San Camillo Hospital; RomeCommunity Outpatient Clinic; Rome-Gemelli Hospital; BergamoInpatient and Outpatient Clinics; Bra-Private Inpatient Clinic; Varese- Inpatient and Outpatient Clinics; Messina-Inpatient and Outpatient Clinics; Perugia-Inpatient Clinic ; Pesaro-Inpatient Clinic; Cuneo- Inpatient Clinic; Biella-Inpatient Clinic.

The protocol was approved by the local Ethics Committees. Patients were diagnosed as affected by BD according to DSM-IV-TR (Diagnostic and Statistical Manual of Mental Disorders) criteria [31].

Diagnoses were made by expert psychiatrists, who had regularly followed up the interviewed patients, and confirmed by the MINI International Neuropsychiatric Interview [32,33]. Patients consecutively presenting at outpatient or inpatient services were selected for the purpose of the study.

Clinical information was obtained through a review of the clinical charts and clinical interviews with patients and available relatives. Data were entered into an electronic central database (electronic Case Report Form: e-CRF). Collected data included the following socio-demographic and clinical variables divided in three clusters:

- cluster 1 (socio-demographic variables): age, gender, education, employment, marital status (at least 1 lifetime marriage or partnership), living alone;

- cluster 2 (lifetime clinical variables): age at onset of BD, age at first pharmacological prescription (including benzodiazepines), age at first contact with psychiatric services, first psychiatric diagnosis, family history of psychiatric disorders (fathers and mothers), age at first psychiatric diagnosis, age at first diagnosis of $\mathrm{BD}$, age at first being prescribed mood stabilizer/atypical antipsychotic, duration of illness, duration of untreated illness, polarity of first episode, lifetime number of manic episodes, lifetime number of depressive episodes, prevalent polarity;

- cluster 3 (clinical variables-last year of observation): type of current episode, number of hypomanic/manic episodes, number of depressive episodes, presence of psychotic symptoms, presence and number of attempted suicides and the degree of lethality, comorbidity with substance use disorders, presence of hospitalizations, presence of insight, attribution of symptoms to a psychiatric disorder, current pharmacological treatment, treatment adherence, number of visits, administration of psychoeducational interventions (according to Colom's model) [34].

Duration of untreated illness was considered as the time between first episode of $\mathrm{BD}$ and the prescription of a proper pharmacological treatment (mood stabilizer or atypical antipsychotic with stabilizing effects) [7,27].

Prevalent polarity was evaluated according to the Barcelona proposal and it was then defined as at least two-thirds $(2 / 3)$ of the total number of past episodes being from the same polarity [35].

Lethality of suicide attempts was rated according to global impression of Scale for Assessment of Lethality of Suicide Attempt (score 1-2: low; score 3: medium; score 4-5: high) [36].

Exclusion criteria included: 1 ) patients who had not been screened in the last 12 months making it impossible to collect data of cluster 3 variables (last year of observation); 2) patients whose clinical information were incomplete; 3) patients with a diagnosis of dementia, mental retardation or other medical conditions (e.g. thyroid disease) potentially associated with an increased risk of RC [37].

The sample size of this cross-sectional study has been calculated in order to have a satisfactorily precision of estimates taking into account the power (0.80) of binomial tests against expected values ranging from 0.05 and 0.30 or 0.70 and 0.95 , carried out at a significance level of 0.05 . In the current case of a very big sample size unbalanced between the two groups, there is "a posteriori" power of more 0.80 for demonstrating a difference of 0.14 from a baseline of 0.50 at a chi-squared test carried out at a significance level of 0.05; in addition, the difference decreases at increasing values of the baseline. Furthermore, with the current sample sizes it is possible to demonstrate at a power of 0.80 an effect size of at least 0.3 at a Student's $t$-test carried out at a significance level of 0.05 (two-tailed).

Descriptive analyses of the total sample were performed. The total sample was then divided in two groups according to the current presence of RC according to DSM-IV-TR criteria, consisting in the presence of at least 4 mood episodes over a 12-month period [31]. We chose to consider the current presence of RC (in the last year) since, as mentioned before, this phenomenon seems to be transient [20]. The two groups were compared for the 
abovementioned variables by t-tests for quantitative variables and chi-square tests for qualitative ones.

Owing to the large number of variables statistically related to the dependent variable (the presence of current RC) at the univariate analyses, preliminary multiple logistic regression analyses (one for each of the abovementioned clusters) were performed including only statistically significant variables. Finally, statistically significant variables from these final models were inserted in a new global starting multivariable logistic regression model to obtain the variables independently associated with the presence of current RC. Age, despite a statistically non-significant variable at univariate analysis, was inserted in the final model because the likelihood of developing rapid-cycling increases with the duration and chronicity of BD [11,38].

The selection of the variables was done according to a backward procedure; the goodness of fitting was assessed by the HosmerLemeshow test.

The level of statistical significance was set at $\mathrm{p} \leq 0.05$. Statistical analyses were performed by $\mathrm{SAS} \circledast 9.2$ version.

\section{Results}

The total sample included 1675 patients: 714 males (42.6\%) and 961 females (57.4\%). Overall, 128 patients of the total sample presented current RC (7.64\%). Patients had an age between 18 and 80 (mean: $48.61 \pm 13.44$ ). Descriptive analyses of the total sample and groups divided according to the presence of current RC are reported in Tables 1,2 and 3.

$\mathrm{RC}$ versus non-RC patients resulted to be more frequently of female gender $(p=0.03)$ and to have more frequently: a first diagnosis of BD, family history of psychiatric disorders and specifically of Major Depressive Disorder (patients' mothers) $(p=0.04)$, comorbid eating disorders and substance misuse $(p=0.04)$, a longer duration of illness $(p=0.04)$, a lifetime number of manic $(p<0.01)$ or depressive episodes $(p<0.01) \geq 6$, an unidentifiable prevalent polarity $(p=0.03)$, history of psychotic symptoms in the last year $(\mathrm{p}<0.01)$, a higher number of suicide attempts in the last year ( $\mathrm{p}<0.01)$, poor insight $(\mathrm{p}<0.01)$, and positive history of at least one hospitalization in the last year $(\mathrm{p}<0.01)$. In addition, patients with $\mathrm{RC}$ had less frequently a current treatment with mood stabilizers $(p=0.03)$ and antidepressants (others than tricyclic ones) $(\mathrm{p}=0.02)$.

The results of the goodness-of-fit-test (Hosmer and Lemeshow Test: $\chi^{2}=2.28, \mathrm{df}=8, \mathrm{p}=0.97$ ) showed that multivariable logistic regression model including socio-demographic/clinical variables as possible predictors of the current presence of $\mathrm{RC}$ was reliable. Of note, patients with RC versus non-RC subjects resulted: to be less frequently of male gender $(\mathrm{OR}=0.64, \mathrm{p}=0.04)$, to have more frequently no lifetime depressive episodes than a lifetime number of depressive episodes between 1 and 5 ( 0 versus $1-2$ episodes: OR $2.87, \mathrm{p}<0.01 ; 0$ versus $3-5$ episodes: $\mathrm{OR}=5.29, \mathrm{p}<0.01$ ), to have less frequently no lifetime manic episodes than more than 6 lifetime manic episodes $(\mathrm{OR}=0.57, \mathrm{p}=0.06$, borderline statistical significance), to present more frequently an unidentifiable prevalent polarity than a depressive $(\mathrm{OR}=1.76, \mathrm{p}=0.02)$ or hypomanic/manic one $(\mathrm{OR}=2.86, \mathrm{p}<0.01)$, to be more frequently hospitalized in the last year (no hospitalizations versus at least 1 hospitalization: $\mathrm{OR}=0.63, \mathrm{p}=0.02$ ) (Table 4, Fig. 1 ).

\section{Discussion}

The first relevant epidemiologic finding of the present largesample multicentric study is represented by the current prevalence of RC in BD, which was found to be $7.65 \%$ of the overall sample. This figure is inferior to those reported in other papers [39], but this can be explained by different reasons including the type of assessment of RC (e.g. current versus lifetime), the way of selection (e.g. in general medicine services or psychiatry clinics or community) or the tools used to make diagnosis (e.g. MINI versus CIDI- Composite International Diagnostic Interview) [40].

The results of the present manuscript confirm that the current presence of $\mathrm{RC}$ in $\mathrm{BD}$ is associated with a series of unfavourable characteristics, including: a longer duration of illness, more lifetime manic episodes $(\geq 6)$, a higher recent number of depressive and hypomanic episodes, a higher number (but not the presence) of recent suicide attempts, a higher frequency of psychotic symptoms (in the last year) and of family history of psychiatric disorders (patients' mothers), poor insight and a higher frequency of recent hospitalization (in the last year). The results are even more robust (having been confirmed by multivariable regression model) regarding the association between $\mathrm{RC}$ with female gender and recent hospitalization (in the last year).

The association between RC and a longer duration of illness has been reported in other socio-cultural contexts [22,41], supporting the hypothesis of some authors that consider RC a transient phenomenon [17-19,42] which could be more frequent in the advanced stages of illness. In this sense, RC could be considered a clinical marker of chronicity [18] rather than a variable of poor prognosis of subjects with recent onset of illness.

It is not surprising that patients with RC present more family history for psychiatric disorders only on the maternal side, as mothers are those who transmit more genetic material to the offspring through mitochondrial DNA [43]; the interesting result is that mothers with MDD, but not BD would appear to confer

Table 1

Socio-demographic variables of the total sample and of the two groups divided according to the presence of current rapid-cycling.

\begin{tabular}{|c|c|c|c|c|c|}
\hline Variables & & $\begin{array}{l}\text { Total Sample } \\
\mathrm{N}=1675\end{array}$ & $\begin{array}{l}\text { Absence of current rapid-cycling } \\
\mathrm{N}=1547(92.36 \%)\end{array}$ & $\begin{array}{l}\text { Presence of current rapid-cycling } \\
\mathrm{N}=128(7.64 \%)\end{array}$ & $\mathrm{p}$ \\
\hline \multirow[t]{2}{*}{ Gender } & Male & $714(42.6 \%)$ & $671(43.4 \%)$ & $43(33.6 \%)$ & 0.03 \\
\hline & Female & $961(57.4 \%)$ & $876(56.6 \%)$ & $85(66.4 \%)$ & \\
\hline Education & $<13$ & $605(36.2 \%)$ & $557(36.1 \%)$ & $48(37.8 \%)$ & 0.36 \\
\hline (years) & $<16$ & $749(44.9 \%)$ & $688(44.6 \%)$ & $61(48.0 \%)$ & \\
\hline Missing $\mathrm{n}=5$ & $\geq 16$ & $316(18.9 \%)$ & $298(19.3 \%)$ & $18(14.2 \%)$ & \\
\hline Employed & $\bar{Y}$ Yes & $1266(75.7 \%)$ & $1174(76.0 \%)$ & $92(71.9 \%)$ & 0.29 \\
\hline Missing $\mathrm{n}=3$ & No & $406(24.3 \%)$ & $370(24.0 \%)$ & $36(28.1 \%)$ & \\
\hline Marriage or Partnership & $\geq 1$ & $1140(68.1 \%)$ & $1055(68.3 \%)$ & $85(66.4 \%)$ & 0.66 \\
\hline Missing $\mathrm{n}=2$ & Never & 533 (31.9\%) & $490(31.7 \%)$ & $43(33.6 \%)$ & \\
\hline Living alone & Yes & $287(17.1 \%)$ & $268(17.3 \%)$ & $19(14.8 \%)$ & 0.47 \\
\hline Missing = 2 & No & $1386(82.9 \%)$ & $1277(82.7 \%)$ & $109(85.2 \%)$ & \\
\hline Age $^{*}$ & & $48.61( \pm 13.44)$ & $48.56( \pm 13.44)$ & $49.28( \pm 13.40)$ & 0.56 \\
\hline
\end{tabular}

Standard deviations are reported into brackets for the variable "age".

In bold statistically significant p resulting from $\chi 2$ and from unpaired Student's $t$-test for the variable "age".

Age is referred to the time of inclusion in the study. 
Table 2

Clinical variables of the total sample and of the two groups divided according to the presence of current rapid-cycling.

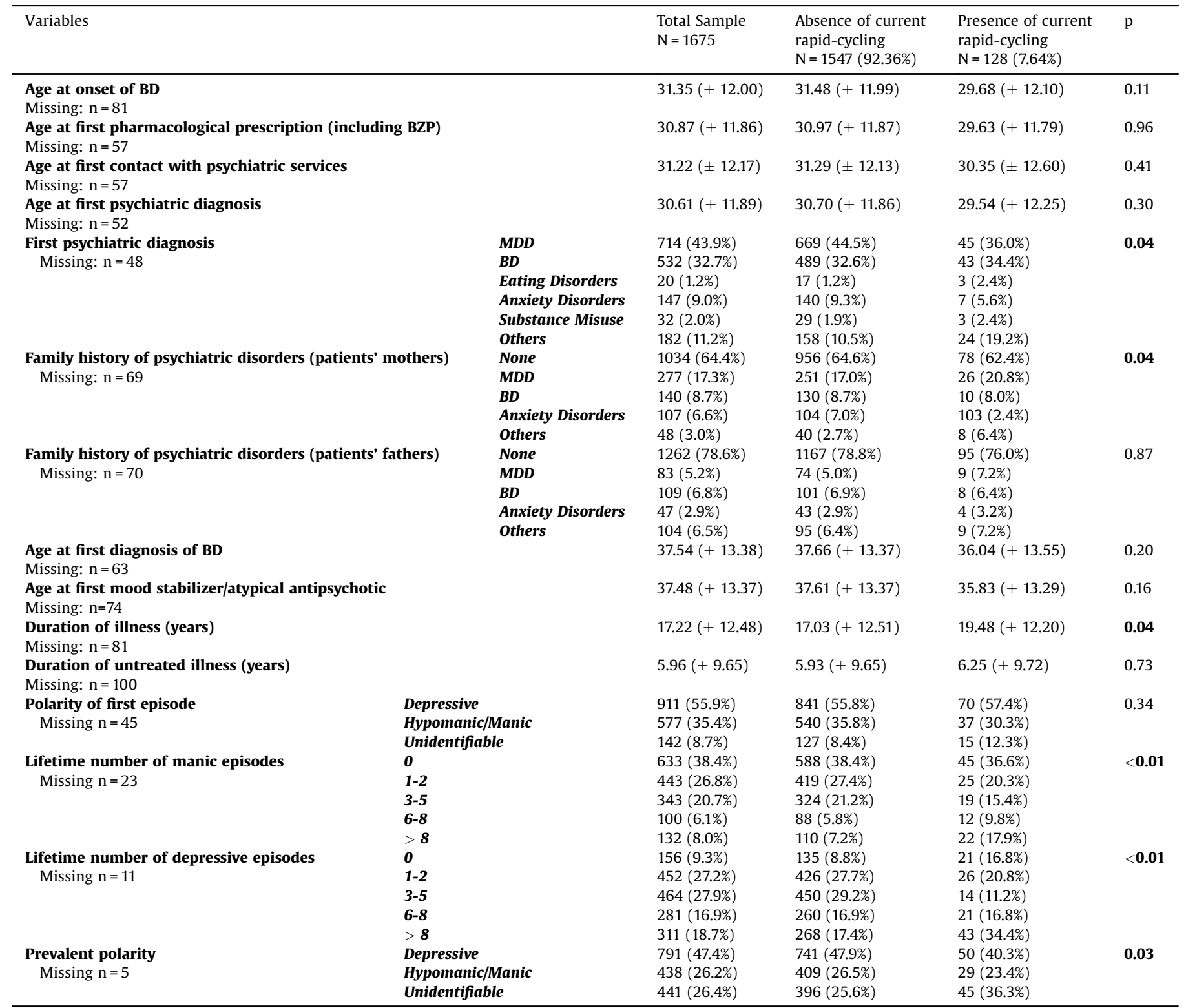

Standard deviations are reported into brackets.

In bold statistically significant p resulting from $\chi 2$ or unpaired Student's $t$-test.

BZP: benzodiazepines.

BD: Bipolar Disorder.

MDD: Major Depressive Disorder.

vulnerability to RC in offspring affected by BD. This finding should be interpreted with caution, taking also into account that female gender is more vulnerable to both RC and MDD [44], and this aspect could have contributed to a significant result for mother and not fathers. However, the higher probability of MDD in mothers of $\mathrm{RC}$ patients is in agreement with previous studies reporting more frequent family history of BD [45] or Panic Disorder [46] in RC versus NRC patients, supporting the view that this subtype of BD would be expression of a more prominent predisposition to psychiatric conditions.

Different studies have reported no association of psychotic symptoms with RC [47,48], differently of what was found in our sample. However, it needs to be highlighted that the statistical significance of this variable did not persist in the final model, and that this result can be due to the type of assessment of psychotic symptoms (lifetime versus current) and/or to the fact that in our and other samples [49] RC patients presented more manic episodes compared to NRC individuals. A higher number of suicide attempts in RC versus NRC patients has been previously reported by European $[19,50]$ and extra-European studies [22,51]. Of note, female gender has been associated with suicide attempts in RC patients [52], supporting the hypothesis of a crucial role of sex hormones on the clinical course of BD [53]. Similarly, a higher presence of poor insight in RC versus NRC subjects has been reported by other authors [54], this aspect being consistent with the supposed long duration of illness and more advanced staging of this subtype of patients [55]. Finally, subjects with RC resulted to receive less frequently a current treatment with mood stabilizers 
Table 3

Clinical variables of the total sample and of the two groups divided according to the presence of current rapid-cycling (last year of observation).

\begin{tabular}{|c|c|c|c|c|c|}
\hline Variables & & $\begin{array}{l}\text { Total Sample } \\
\mathrm{N}=1675\end{array}$ & $\begin{array}{l}\text { Absence of current } \\
\text { rapid-cycling } \\
\mathrm{N}=1547(92.36 \%)\end{array}$ & $\begin{array}{l}\text { Presence of current } \\
\text { rapid-cycling } \\
\mathrm{N}=128(7.64 \%)\end{array}$ & $\mathrm{p}$ \\
\hline $\begin{array}{l}\text { Type of current episode } \\
\text { Missing: } n=0\end{array}$ & $\begin{array}{l}\text { Depressive } \\
\text { Manic } \\
\text { Hypomanic } \\
\text { Mixed } \\
\text { Euthymia }\end{array}$ & $\begin{array}{l}242(14.4 \%) \\
198(11.8 \%) \\
26(1.6 \%) \\
150(9.0 \%) \\
1059(63.2 \%)\end{array}$ & $\begin{array}{l}226(14.6 \%) \\
179(11.6 \%) \\
25(1.6 \%) \\
129(8.3 \%) \\
988(63.9 \%)\end{array}$ & $\begin{array}{l}16(12.5 \%) \\
19(14.8 \%) \\
1(0.8 \%) \\
21(16.4 \%) \\
71(55.5 \%)\end{array}$ & 0.07 \\
\hline $\begin{array}{l}\text { Number of depressive episodes } \\
\text { Missing: } n=0\end{array}$ & & $1.48( \pm 1.03)$ & $1.45( \pm 1.00)$ & $1.78( \pm 1.44)$ & $<\mathbf{0 . 0 1}$ \\
\hline $\begin{array}{l}\text { Number of manic episodes } \\
\text { Missing: } n=0\end{array}$ & & $1.31( \pm 0.80)$ & $1.29( \pm 0.75)$ & $1.55( \pm 1.45)$ & 0.65 \\
\hline $\begin{array}{l}\text { Number of hypomanic episodes } \\
\text { Missing: } n=0\end{array}$ & & $1.36( \pm 0.99)$ & $1.33( \pm 0.96)$ & $1.74( \pm 1.36)$ & 0.03 \\
\hline $\begin{array}{l}\text { Number of mixed episodes } \\
\text { Missing: } n=0\end{array}$ & & $1.53( \pm 1.25)$ & $1.53( \pm 1.29)$ & $1.56( \pm 0.82)$ & 0.08 \\
\hline $\begin{array}{l}\text { Presence of psychotic symptoms } \\
\text { Missing: } n=5\end{array}$ & & $\begin{array}{l}1263(75.6 \%) \\
407(24.4 \%)\end{array}$ & $\begin{array}{l}1181(76.5 \%) \\
362(23.5 \%)\end{array}$ & $\begin{array}{l}82(64.6 \%) \\
45(35.4 \%)\end{array}$ & $<\mathbf{0 . 0 1}$ \\
\hline $\begin{array}{l}\text { Attempted suicides } \\
\text { Missing: } n=1\end{array}$ & $\begin{array}{l}\text { No } \\
\text { Yes }\end{array}$ & $\begin{array}{l}1559(93.1 \%) \\
115(6.9 \%)\end{array}$ & $\begin{array}{l}1442(93.2 \%) \\
105(6.8 \%)\end{array}$ & $\begin{array}{l}117(92.1 \%) \\
10(7.9 \%)\end{array}$ & 0.64 \\
\hline Degree of lethality of attempted suicides & $\begin{array}{l}\text { Low } \\
\text { Medium } \\
\text { High }\end{array}$ & $\begin{array}{l}52(45.2 \%) \\
44(38.3 \%) \\
19(16.5 \%)\end{array}$ & $\begin{array}{l}50(47.6 \%) \\
40(38.1 \%) \\
15(14.3 \%)\end{array}$ & $\begin{array}{l}2(20.0 \%) \\
4(40.0 \%) \\
4(40.0 \%)\end{array}$ & 0.07 \\
\hline $\begin{array}{l}\text { Number of attempted suicides } \\
\text { Missing: } n=4\end{array}$ & $\begin{array}{l}0 \\
1 \\
2 \\
3\end{array}$ & $\begin{array}{l}1559(93.3 \%) \\
92(5.5 \%) \\
12(0.7 \%) \\
8(0.5 \%)\end{array}$ & $\begin{array}{l}1442(93.4 \%) \\
85(5.5 \%) \\
12(0.8 \%) \\
5(0.3 \%)\end{array}$ & $\begin{array}{l}117(92.1 \%) \\
7(5.5 \%) \\
0(0.0 \%) \\
3(2.4 \%)\end{array}$ & $<\mathbf{0 . 0 1}$ \\
\hline $\begin{array}{l}\text { Insight } \\
\quad \text { Missing: } n=3\end{array}$ & $\begin{array}{l}\text { No } \\
\text { Yes } \\
\text { Partial }\end{array}$ & $\begin{array}{l}78(4.7 \%) \\
1165(69.7) \\
427(25.6 \%)\end{array}$ & $\begin{array}{l}71(4.6 \%) \\
1091(70.6 \%) \\
383(24.8 \%)\end{array}$ & $\begin{array}{l}7(5.5 \%) \\
74(58.3 \%) \\
46(36.2 \%)\end{array}$ & 0.01 \\
\hline $\begin{array}{l}\text { Attribution of symptoms to a psychiatric disorder } \\
\text { Missing: } n=4\end{array}$ & $\begin{array}{l}\text { No } \\
\text { Yes } \\
\text { Partial }\end{array}$ & $\begin{array}{l}131(7.9 \%) \\
1065(63.7 \%) \\
475(28.4 \%)\end{array}$ & $\begin{array}{l}119(7.7 \%) \\
991(64.2 \%) \\
434(28.1 \%)\end{array}$ & $\begin{array}{l}12(9.4 \%) \\
74(58.3 \%) \\
41(32.3 \%)\end{array}$ & 0.40 \\
\hline $\begin{array}{l}\text { Current pharmacological treatment } \\
\text { Missing: } n=0\end{array}$ & $\begin{array}{l}\text { Mood Stabilizers } \\
\text { Tricyclic Antidepressants } \\
\text { Antidepressants } \\
\text { (excluding Tricyclics) }\end{array}$ & $\begin{array}{l}1196(71.40 \%) \\
142(8.5 \%) \\
490(29.3 \%)\end{array}$ & $\begin{array}{l}1115(72.1 \%) \\
131(8.5 \%) \\
464(30.0 \%)\end{array}$ & $\begin{array}{l}81(63.3 \%) \\
11(8.6 \%) \\
26(20.3 \%)\end{array}$ & $\begin{array}{l}\mathbf{0 . 0 3} \\
0.96 \\
\mathbf{0 . 0 2}\end{array}$ \\
\hline & $\begin{array}{l}\text { Antipsychotics } \\
\text { Benzodiazepines }\end{array}$ & $\begin{array}{l}997(59.5 \%) \\
469(28.0 \%)\end{array}$ & $\begin{array}{l}918(59.3 \%) \\
440(28.44 \%)\end{array}$ & $\begin{array}{l}79(61.7 \%) \\
29(22.66 \%)\end{array}$ & $\begin{array}{l}0.60 \\
0.16\end{array}$ \\
\hline $\begin{array}{l}\text { Treatment } \\
\text { Adherence } \\
\text { Missing: } \mathrm{n}=8\end{array}$ & $\begin{array}{l}\text { No } \\
\text { Yes } \\
\text { Partial }\end{array}$ & $\begin{array}{l}124(7.4 \%) \\
1156(69.4 \%) \\
387(23.2 \%)\end{array}$ & $\begin{array}{l}112(7.3 \%) \\
1073(69.7 \%) \\
355(23.0 \%)\end{array}$ & $\begin{array}{l}12(9.5 \%) \\
83(65.3 \%) \\
32(25.2 \%)\end{array}$ & 0.52 \\
\hline $\begin{array}{l}\text { Number of visits } \\
\text { Missing: } \mathrm{n}=0\end{array}$ & & $9.67( \pm 9.09)$ & $9.67( \pm 9.16)$ & $9.70( \pm 8.37)$ & 0.66 \\
\hline $\begin{array}{l}\text { Psychoeducation } \\
\text { Missing: } n=9\end{array}$ & $\begin{array}{l}\text { Individual } \\
\text { Group } \\
\text { No }\end{array}$ & $\begin{array}{l}122(7.3 \%) \\
149(9.0 \%) \\
1395(83.7 \%)\end{array}$ & $\begin{array}{l}117(7.6 \%) \\
135(8.8 \%) \\
1289(83.6 \%)\end{array}$ & $\begin{array}{l}5(4.0 \%) \\
14(11.2 \%) \\
106(84.8 \%)\end{array}$ & 0.24 \\
\hline $\begin{array}{l}\text { Substance } \\
\text { Misuse } \\
\text { Missing: } n=2\end{array}$ & $\begin{array}{l}\text { No } \\
\text { Yes }\end{array}$ & $\begin{array}{l}1472(88.0 \%) \\
201(12.0 \%)\end{array}$ & $\begin{array}{l}1358(87.8 \%) \\
188(12.2 \%)\end{array}$ & $\begin{array}{l}114(89.8 \%) \\
13(10.2 \%)\end{array}$ & 0.52 \\
\hline $\begin{array}{r}\text { Hospitalization } \\
\text { Missing: } n=1\end{array}$ & $\begin{array}{l}\text { No } \\
\text { Yes }\end{array}$ & $\begin{array}{l}988(59.0 \%) \\
686(41.0 \%)\end{array}$ & $\begin{array}{l}929(60.1 \%) \\
618(39.9 \%)\end{array}$ & $\begin{array}{l}59(46.5 \%) \\
68(53.5 \%)\end{array}$ & $<\mathbf{0 . 0 1}$ \\
\hline
\end{tabular}

In bold statistically significant p resulting from $\chi 2$ or unpaired Student's $t$-test.

Standard deviations are reported into brackets.

and antidepressants. This result is in agreement with previous literature that reports less efficacy of lithium in RC versus NRC patients [56] and a potential role of antidepressants in the development and worsening of RC [57].

The two most robust results of the present manuscript, remaining statistically significant in the final multivariable model, are the associations of $\mathrm{RC}$ with female gender and recent hospitalization. Indeed, a higher frequency of RC in women than men is one of the most replicated findings across studies about this topic [58]. Different hypotheses have been formulated about the association of female gender with $\mathrm{RC}$, including the fact that some risk factors for RC are more prevalent in women than in men, such as cyclothymia [58] or suicidal ideation [19]. Other authors have hypothesized that female gender is more susceptible to RC as a result of higher frequency of BD type 2 in women than men $[39,59]$; however, a previous analysis on our sample about differences between patients with BD 1 versus 2 did not reveal a significant association of type of cycling with bipolar subtype [60]. Finally, the result of a higher frequency of recent hospitalization in RC versus NRC subjects is of clinical interest, as it stresses how pharmacological stabilization of these patients can be challenging [61] and that this particular subtype of BD requires careful monitoring to avoid social impairment and elevated costs associated with frequent hospitalization [62].

Taken as a whole, the results of the present manuscript would confirm that RC can be considered a marker of more advanced staging of illness and that RC patients require careful clinical monitoring to prevent recurrent hospitalization also in the light of a more frequently observed poor compliance. These findings are in agreement with previous literature. Finally, female gender is at risk of RC and women affected by BD should receive a personalized treatment aimed to guarantee clinical stabilization. Future research would investigate the 
Table 4

Summary of the statistics for the best-fit multivariable logistic regression model applied (variables associated with current presence of rapid-cycling).

\begin{tabular}{|c|c|c|c|c|}
\hline Variables & Categories & Odds Ratio & $95 \% \mathrm{CI}$ & $\mathrm{p}$ \\
\hline Gender & Male vs Female & 0.64 & $0.43-0.97$ & 0.04 \\
\hline Age & NA & 1.00 & 0.99-1.02 & 0.90 \\
\hline \multirow[t]{3}{*}{ Number of lifetime depressive episodes } & 0 vs $1-2$ & 2.87 & $1.47-5.59$ & $<\mathbf{0 . 0 1}$ \\
\hline & 0 vs $3-5$ & 5.29 & $2.42-11.53$ & $<\mathbf{0 . 0 1}$ \\
\hline & 0 vs $\geq 6$ & 1.76 & $0.88-3.49$ & 0.11 \\
\hline \multirow[t]{3}{*}{ Number of lifetime manic episodes } & 0 vs $1-2$ & 1.37 & $0.80-2.34$ & 0.25 \\
\hline & 0 vs $3-5$ & 1.20 & $0.66-2.21$ & 0.54 \\
\hline & $0 \mathrm{vs} \geq 6$ & 0.57 & $0.32-1.02$ & $0.06^{*}$ \\
\hline \multirow[t]{2}{*}{ Prevalent Polarity } & Unidentifiable vs Depressive & 1.76 & $1.10-2.83$ & 0.02 \\
\hline & Unidentifiable vs Hypomanic/Manic & 2.86 & $1.59-5.14$ & $<\mathbf{0 . 0 1}$ \\
\hline \multirow[t]{2}{*}{ Insight } & No vs Partial & 0.86 & $0.35-2.09$ & 0.74 \\
\hline & No vs Yes & 1.56 & $0.64-3.79$ & 0.33 \\
\hline Hospitalization in the last year & No vs Yes & 0.63 & $0.43-0.94$ & 0.02 \\
\hline
\end{tabular}

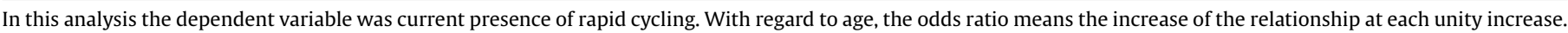
Hosmer-Lemeshow test: $\chi 2=2.28, \mathrm{df}=8, \mathrm{p}=0.97$.

$\mathrm{Vs}=$ versus $; \mathrm{NA}=$ not applicable $; 95 \% \mathrm{CI}=95 \%$ Confidence Interval; $\mathrm{p}=$ significance $\mathrm{p}$-values

In bold statistically significant p-values.

borderline statistically significant.

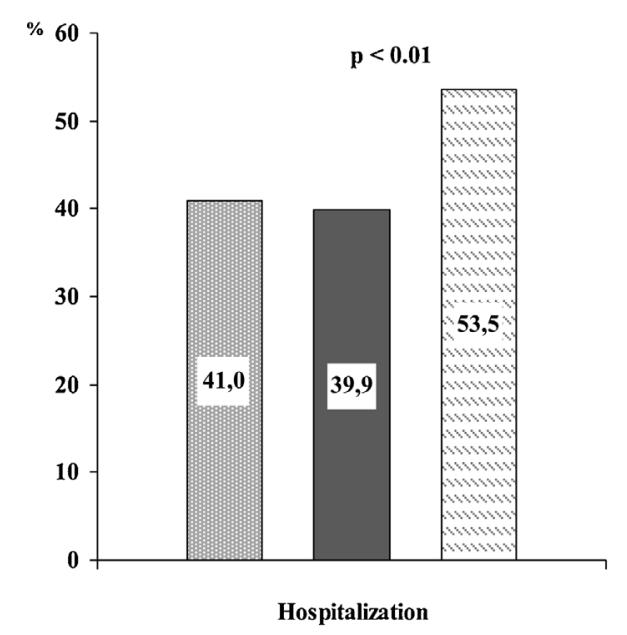

$\square$ Total Sample $\square$ Non-Rapid Cycling Patients $\square$ Rapid Cycling Patients

Fig. 1. Frequency of at least one hospitalization in the last year of observation between rapid-cycling and non-rapid cycling patients.

interconnection between different variables associated with $\mathrm{BD}$ outcome such as suicidal ideation, female gender and RC.

These limitations of the present research article need to be taken into account:

1) the different settings of care (in several Italian regions) may have impacted on the clinical features of the sample (e.g. the availability of psychoeducation to improve insight of patients with $\mathrm{BD})$;

2) some data were collected retrospectively (e.g. number of mood episodes) and they might have not been always as accurate as in controlled studies;

3 ) the lack of a prospective monitoring due to the crosssectional nature of the study;

4) the limited number of RC patients;

5) the impossibility to extrapolate data for the single pharmacological compounds (e.g. lithium);

6) the lack of complete information about family history of psychiatric disorders;

7) patients received a treatment which might have influenced some clinical features (e.g. some compounds might be more effective in the clinical stabilization of RC patients) [16]. With regard to the last point it has been highlighted that in our sample the only compounds that resulted to be differently prescribed in the two groups in the last year were mood stabilizers and antidepressants (other than tricyclics). Antidepressants were more frequently prescribed in patients without rapid-cycling so that the administration of these compounds has not massively influenced the main results of this research (the association of RC with female gender and recent hospitalization). Mood stabilizers have a comparable effect on RC [16]; olanzapine and aripiprazole are reported to be promising in the long-term treatment of patients with RC [16], we have no information about the administration of single compounds, however the groups divided according to the presence of RC did not present a statistically significant difference in the frequency of prescription of antipsychotics.

\section{Ethical approval}

The study was approved by local Ethics Committee

\section{Declaration of Competing Interest}

None with the present manuscript

\section{Acknowledgments}

The authors thank all the centers that have given the availability to participate in this study. Herein a list of collaborators:

- Prof Mario Amore, University of Genoa.

- Prof Antonello Bellomo, University of Foggia.

- Prof Alessandro Bertolino, University of Bari.

- Dr. Emi Bondi, Hospital Papa Giovanni XXIII, Bergamo.

- Prof Andrea de Bartolomeis, University of Naples "Federico II".

- Dr Marco Di Nicola, Università Cattolica del Sacro Cuore, Rome.

- Dr Guido Di Sciascio, University of Bari.

- Prof Silvana Galderisi, University of Campania "Luigi Vanvitelli", Naples.

- Prof Maurizio Pompili, Sant'Andrea Hospital, Sapienza University of Rome.

- Prof Paola Rocca, University of Turin.

- Prof Emilio Sacchetti, University of Brescia.

- Prof Gabriele Sani, Sapienza University of Rome.

- Prof Alberto Siracusano, University of Rome "Tor Vergata".

- Prof Alfonso Tortorella, University of Perugia. 


\section{References}

[1] Grande I, Berk M, Birmaher B, Vieta E. Bipolar disorder. Lancet 2016;387:1561-72.

[2] Merikangas KR, Jin R, He JP, Kessler RC, Lee S, Sampson NA, et al. Prevalence and correlates of bipolar spectrum disorder in the world mental health survey initiative. Arch Gen Psychiatry 2011;68:241-51.

[3] Moreira ALR, Van Meter A, Genzlinger J, Youngstrom EA. Review and metaanalysis of epidemiologic studies of adult bipolar disorder. J Clin Psychiatry 2017;78:e1259-69.

[4] Carta MG, Aguglia E, Balestrieri M, Calabrese JR, Caraci F, Dell'Osso L, et al. The lifetime prevalence of bipolar disorders and the use of antidepressant drugs in bipolar depression in Italy. J Affect Disord 2012;136:775-80.

[5] Granek L, Danan D, Bersudsky Y, Osher Y. Living with bipolar disorder: the impact on patients, spouses, and their marital relationship. Bipolar Disord 2016;18:192-9.

[6] Baldessarini RJ, Bolzani L, Cruz N, Jones PB, Lai M, Lepri B, et al. Onset-age of bipolar disorders at six international sites. J Affect Disord 2010;121:143-6.

[7] Altamura AC, Buoli M, Caldiroli A, Caron L, Cumerlato Melter C, Dobrea C, et al Misdiagnosis, duration of untreated illness (DUI) and outcome in bipolar patients with psychotic symptoms: a naturalistic study. J Affect Disord 2015;182:70-5.

[8] Arici C, Cremaschi L, Dobrea C, Vismara M, Grancini B, Benatti B, et al. Differentiating multiple vs single lifetime suicide attempters with bipolar disorders: A retrospective study. Compr Psychiatry 2018;80:214-22.

[9] Connor DF, Ford JD, Pearson GS, Scranton VL. Dusad A. Early-onset bipolar disorder: characteristics and outcomes in the clinic. J Child Adolesc Psychopharmacol 2017;27:875-83.

[10] Almeida OP, Hankey GJ, Yeap BB, Golledge J, Flicker L. Older men with bipolar disorder: clinical associations with early and late onset illness. Int J Geriatr Psychiatry 2018;33:1613-9.

[11] Altamura AC, Serati M, Buoli M. Is duration of illness really influencing outcome in major psychoses? Nord J Psychiatry 2015;69:403-17.

[12] Drancourt N, Etain B, Lajnef M, Henry C, Raust A, Cochet B, et al. Duration of untreated bipolar disorder: missed opportunities on the long road to optimal treatment. Acta Psychiatr Scand 2013;127:136-44.

[13] Ostergaard SD, Bertelsen A, Nielsen J, Mors O, Petrides G. The association between psychotic mania, psychotic depression and mixed affective episodes among 14,529 patients with bipolar disorder. J Affect Disord 2013; 147:44-50.

[14] Altamura AC, Buoli M, Cesana BM, Fagiolini A, de Bartolomeis A, Maina G, et al. Psychotic versus non-psychotic Bipolar Disorder: socio-demographic and clinical profiles in an Italian nationwide study. Aust N Z J Psychiatry 2019, doi: http://dx.doi.org/10.1177/0004867418823268 in press.

[15] Dell'Osso B, Camuri G, Cremaschi L, Dobrea C, Buoli M, Ketter TA, et al. Lifetime presence of psychotic symptoms in bipolar disorder is associated with less favorable socio-demographic and certain clinical features. Compr Psychiatry 2017:76:169-76.

[16] Fountoulakis KN, Kontis D, Gonda X, Yatham LN. A systematic review of the evidence on the treatment of rapid cycling bipolar disorder. Bipolar Disord 2013;15:115-37.

[17] Buoli M, Cesana BM, Dell'Osso B, Fagiolini A, de Bartolomeis A, Bondi E, et al. ISBD italian chapter epidemiological group. Gender-related differences in patients with bipolar disorder: a nationwide study. CNS Spectr 2018 in press.

[18] Carvalho AF, Dimellis D, Gonda X, Vieta E, Mclntyre RS, Fountoulakis KN. Rapid cycling in bipolar disorder: a systematic review. J Clin Psychiatry 2014;75: e578-86.

[19] Valentí M, Pacchiarotti I, Undurraga J, Bonnín CM, Popovic D, Goikolea JM, et al. Risk factors for rapid cycling in bipolar disorder. Bipolar Disord 2015; 17:549-59.

[20] Bauer M, Beaulieu S, Dunner DL, Lafer B, Kupka R. Rapid cycling bipolar disorder-diagnostic concepts. Bipolar Disord 2008;10:153-62.

[21] El-Mallakh RS, Vöhringer PA, Ostacher MM, Baldassano CF, Holtzman NS, Whitham EA, et al. Antidepressants worsen rapid-cycling course in bipolar depression: a STEP-BD randomized clinical trial. J Affect Disord 2015;184:318-21.

[22] Gigante AD, Barenboim IY, Dias RD, Toniolo RA, Mendonça T, Miranda-Scippa $\hat{A}$, et al. Psychiatric and clinical correlates of rapid cycling bipolar disorder: a cross-sectional study. Rev Bras Psiquiatr 2016;38:270-4.

[23] Buoli M, Dell’Osso B, Caldiroli A, Carnevali GS, Serati M, Suppes T, et al. Obesity and obstetric complications are associated with rapid-cycling in Italian patients with bipolar disorder. J Affect Disord 2017;208:278-83.

[24] Ruzickova M, Slaney C, Garnham J, Alda M. Clinical features of bipolar disorder with and without comorbid diabetes mellitus. Can J Psychiatry 2003;48:458-61.

[25] Reed C, Goetz I, Vieta E, Bassi M, Haro JM, EMBLEM Advisory Board. Work impairment in bipolar disorder patients-results from a two-year observational study (EMBLEM). Eur Psychiatry 2010;25:338-44.

[26] Suppes T, Brown E, Schuh LM, Baker RW, Tohen M. Rapid versus non-rapid cycling as a predictor of response to olanzapine and divalproex sodium for bipolar mania and maintenance of remission: post hoc analyses of 47 -week data. J Affect Disord 2005;89:69-77.

[27] Buoli M, Serati M, Altamura AC. Is the combination of a mood stabilizer plus an antipsychotic more effective than mono-therapies in long-term treatment of bipolar disorder? A systematic review. J Affect Disord 2014;152-154:12-8.
[28] Papadimitriou GN, Dikeos DG, Soldatos CR, Calabrese JR. Non-pharmacological treatments in the management of rapid cycling bipolar disorder. J Affect Disord 2007;98:1-10.

[29] Buoli M, Serati M, Altamura AC. Biological aspects and candidate biomarkers for rapid-cycling in bipolar disorder: a systematic review. Psychiatry Res 2017;258:565-75.

[30] Joslyn C, Hawes DJ, Hunt C, Mitchell PB. Is age of onset associated with severity, prognosis, and clinical features in bipolar disorder? A meta-analytic review. Bipolar Disord 2016;18:389-403.

[31] American Psychiatric Association. Diagnostic and statistical manual of mental disorders. 4th edition Washington DC: American Psychiatric Press; 2000 Text Revision (DSM-IV-TR)

[32] Sheehan DV, Lecrubier Y, Sheehan KH, Amorim P, Janavs J, Weiller E, et al. The Mini-International Neuropsychiatric Interview (M.I.N.I.): the development and validation of a structured diagnostic psychiatric interview for DSM-IV and ICD-10. J Clin Psychiatry 1998;59:22-33.

[33] Buoli M, Cesana BM, Barkin JL, Tacchini G, Altamura AC. Validity of a clinical diagnosis of bipolar disorder among participants in a multicenter study using the Mini-International Neuropsychiatric Interview. Bipolar Disord 2018;20:284.

[34] Vieta E, Pacchiarotti I, Valentí M, Berk L, Scott J, Colom F. A critical update on psychological interventions for bipolar disorders. Curr Psychiatry Rep 2009;11:494-502.

[35] Colom F, Vieta E, Suppes T. Predominant polarity in bipolar disorders: refining or redefining diagnosis? Acta Psychiatr Scand 2015;132:324-6.

[36] Kar N, Arun M, Mohanty MK, Bastia BK. Scale for assessment of lethality of suicide attempt. Indian J Psychiatry 2014;56:337-43.

[37] Lorenzo Gómez T, Cardelle Pérez F, De Las Heras Liñero E. The high prevalence of thyroid dysfunction in psychiatric inpatients. Rev Psiquiatr Salud Ment 2010;3:23-6.

[38] Maj M, Magliano L, Pirozzi R, Marasco C, Guarneri M. Validity of rapid cycling as a course specifi er for bipolar disorder. Am J Psychiatry 1994;151(1015):9.

[39] Kupka RW, Luckenbaugh DA, Post RM, Leverich GS, Nolen WA. Rapid and nonrapid cycling bipolar disorder: a meta-analysis of clinical studies. J Clin Psychiatry 2003;64:1483-94.

[40] Lee S, Tsang A, Kessler RC, et al. Rapid-cycling bipolar disorder: cross-national community study. Br J Psychiatry 2010;196:217-25.

[41] Kupka RW, Luckenbaugh DA, Post RM, Suppes T, Altshuler LL, Keck Jr PE, et al Comparison of rapid-cycling and non-rapidcycling bipolar disorder based on prospective mood ratings in 539 outpatients. Am J Psychiatry 2005;162:1273-80.

[42] Coryell W, Endicott J, Keller M. Rapidly cycling affective disorder Demographics, diagnosis, family history, and course. Arch Gen Psychiatry 1992;49:126-31.

[43] Buoli M, Caldiroli A. IQ as a cognitive marker of genetic liability in relatives of schizophrenia patients. Am J Psychiatry 2015;172:793-4.

[44] Serra G, Koukopoulos A, De Chiara L, Napoletano F, Koukopoulos AE, Curto M et al. Features preceding diagnosis of bipolar versus major depressive disorders. J Affect Disord 2015;173:134-42.

[45] Vieta E, Calabrese JR, Hennen J, Colom F, Martínez-Arán A, Sánchez-Moreno J, et al. Comparison of rapid-cycling and non-rapid-cycling bipolar I manic patients during treatment with olanzapine: analysis of pooled data. J Clin Psychiatry 2004;65:1420-8.

[46] Mackinnon DF, Zandi PP, Gershon ES, Nurnberger Jr JI, DePaulo Jr JR. Association of rapid mood switching with panic disorder and familial panic risk in familial bipolar disorder. Am J Psychiatry 2003;160:1696-8.

[47] Vieta E, Calabrese JR, Hennen J, Colom F, Martínez-Arán A, Sánchez-Moreno J, et al. Comparison of rapid-cycling and non-rapid-cycling bipolar I manic patients during treatment with olanzapine: analysis of pooled data. J Clin Psychiatry 2004;65:1420-8.

[48] Azorin JM, Kaladjian A, Adida M, Hantouche EG, Hameg A, Lancrenon S, CNS Spectr 2008;13:780-7.

[49] Aedo A, Murru A, Sanchez R, Grande I, Vieta E, Undurraga J. Clinical characterization of rapid cycling bipolar disorder: association with attention deficit hyperactivity disorder. J Affect Disord 2018;240:187-92.

[50] Garcia-Amador M, Colom F, Valenti M, Horga G, Vieta E. Suicide risk in rapid cycling bipolar patients. J Affect Disord 2009;117:74-8.

[51] Bobo WV, Na PJ, Geske JR, McElroy SL, Frye MA, Biernacka JM. The relative influence of individual risk factors for attempted suicide in patients with bipolar I versus bipolar II disorder. J Affect Disord 2018;225:489-94.

[52] Gao K, Tolliver BK, Kemp DE, Ganocy SJ, Bilali S, Brady KL, et al. Correlates of historical suicide attempt in rapid-cycling bipolar disorder: a cross-sectional assessment. J Clin Psychiatry 2009;70:1032-40.

[53] Sher L, Grunebaum MF, Sullivan GM, Burke AK, Cooper TB, Mann JJ, et al. Testosterone levels in suicide attempters with bipolar disorder. J Psychiatr Res 2012;46:1267-71.

[54] Jawad I, Watson S, Haddad PM, Talbot PS, McAllister-Williams RH. Medication nonadherence in bipolar disorder: a narrative review. Ther Adv Psychopharmacol 2018;8:349-63.

[55] Kapczinski F, Dias VV, Kauer-Sant'Anna M, Frey BN, Grassi-Oliveira R, Colom F, et al. Clinical implications of a staging model for bipolar disorders. Expert Rev Neurother 2009;9:957-66.

[56] Coryell W, Solomon D, Turvey C, Keller M, Leon AC, Endicott J, et al. The longterm course of rapid-cycling bipolar disorder. Arch Gen Psychiatry 2003;60:914-20. 
[57] Gitlin MJ. Antidepressants in bipolar depression: an enduring controversy. Int J Bipolar Disord 2018;6:25.

[58] Kilzieh N, Akiskal HS. Rapid cycling bipolar disorder. An overview of research and clinical experience. Psychiatr Clin North Am 1999:22:585-607.

[59] Erol A, Winham SJ, McElroy SL, Frye MA, Prieto ML, Cuellar-Barboza AB, et al. Sex differences in the risk of rapid cycling and other indicators of adverse illness course in patients with bipolar I and II disorder. Bipolar Disord $2015 ; 17: 670-6$
[60] Altamura AC, Buoli M, Cesana B, Dell'Osso B, Tacchini G, Albert U, et al. Sociodemographic and clinical characterization of patients with bipolar disorder I vs II: a Nationwide Italian study. Eur Arch Psychiatry Clin Neurosci 2018;268:169-77.

[61] Suppes T, Ozcan ME, Carmody T. Response to clozapine of rapid cycling versus non-cycling patients with a history of mania. Bipolar Disord 2004;6:329-32.

[62] Gianfrancesco F, Rajagopalan K, Goldberg JF, Wang RH. Hospitalization risks in the treatment of bipolar disorder: comparison of antipsychotic medications. Bipolar Disord 2007;9:252-61. 